\title{
Approaches toward improving the modelling of midlatitude cyclones entering at the lateral boundary corner in the limited area model WRF
}

Imberger, Marc; Larsén, Xiaoli Guo; Davis, Neil; Du, Jianting

Published in:

Quarterly Journal of the Royal Meteorological Society

Link to article, DOI:

10.1002/qj.3843

Publication date:

2020

Document Version

Peer reviewed version

Link back to DTU Orbit

Citation (APA):

Imberger, M., Larsén, X. G., Davis, N., \& Du, J. (2020). Approaches toward improving the modelling of mid

latitude cyclones entering at the lateral boundary corner in the limited area model WRF. Quarterly Journal of the Royal Meteorological Society, 146(732), 3225-3244. https://doi.org/10.1002/qi.3843

\section{General rights}

Copyright and moral rights for the publications made accessible in the public portal are retained by the authors and/or other copyright owners and it is a condition of accessing publications that users recognise and abide by the legal requirements associated with these rights.

- Users may download and print one copy of any publication from the public portal for the purpose of private study or research.

- You may not further distribute the material or use it for any profit-making activity or commercial gain

- You may freely distribute the URL identifying the publication in the public portal 


\title{
Approaches toward improving the modelling of mid-latitude cyclones entering at the lateral boundary corner in the limited area model WRF
}

\author{
Marc Imberger ${ }^{1}$ \\ Jianting $\mathrm{Du}^{2}$ \\ ${ }^{1}$ Wind Energy Department, Technical \\ University of Denmark - Risø Campus, \\ Roskilde, Denmark \\ ${ }^{2}$ The First Institute of Oceanography, MNR, \\ Qingdao, China

\section{Correspondence} \\ Marc Imberger, Wind Energy Department, \\ Technical University of Denmark - Risø \\ Campus, Roskilde, Denmark \\ Email: maim@dtu.dk \\ Funding information \\ DTU Wind Energy Department (internal \\ funds) and Danish "OffshoreWake" project \\ (PSO-12521)
}

Xiaoli Guo Larsén ${ }^{1}$

Neil Davis ${ }^{1}$

\section{ABSTRACT}

Lateral boundaries can have a large effect on the introduction of external large-scale structures in limited area models. This case study of a mid-latitude cyclone using the Advanced Weather Research and Forecasting (WRF) model examines challenges in simulating the storm intensity (characterised by sea level pressure, relative vorticity and wind speed) when a storm centre enters close to the lateral boundary corner in the outermost model domain. A domain shift, nudging techniques, adjustments of the WRF relaxation layer and the influence of boundary condition update frequency are investigated as possible solutions. The update frequency of the lateral boundary conditions is found to be the most efficient in improving the storm intensity, while adjustments to the relaxation layer or nudging techniques

This article has been accepted for publication and undergone full peer review but has not been through the copyediting, typesetting, pagination and proofreading process, which may lead to differences between this version and the Version of Record. Please cite this article as doi: $10.1002 /$ qj.3843 
did not overcome the lack of insufficiently updated lateral boundary conditions. This suggests that the modelling of the storm intensification requires sufficiently high temporal resolution.

Keywords: limited area modelling, meso-scale modelling, lateral boundary conditions, mid-latitude cyclone, WRF

\section{1 | INTRODUCTION}

of interest (see e.g. Giorgi (2019) and references therein), and are therefore, also referred to as limited area models (LAMs). LAMs allow for smaller scale features to be resolved, improving the simulation results (e.g. Denis et al. (2002), Feser (2006)), at reduced computational costs, but add lateral boundary conditions (LBCs) as an additional dependence (e.g. Laprise (2003)). However, sharp changes in resolution (horizontal and vertical), between the LBCs and the LAM, can introduce spatial inconsistencies due to the spatial interpolation (Warner et al. (1997)). Additionally, LAMs require

LBCs at every integration time step, typically a few seconds or minutes, while global reanalysis and forecast products are provided with resolutions on the order of hours. This makes temporal interpolation unavoidable (Warner et al. (1997)). Warner et al. (1997) highlighted that the update frequency of LBCs is one of the largest challenges when hing LAMs, noting that it is especially relevant when the update frequency is low in comparison to the timescales of the meteorological feature of interest.

Several studies using HIRLAM (HIgh Resolution Limited Area Model, Källén (1996)) have shown that the influence of LBCs on LAM model results are especially important for cases with strong external forcing, e.g. severe storm events. Gustafsson (1990) found that a higher update frequency provided better forecasts based on the 24-h forecast skill of mean sea level pressure (MSLP) during rapid cyclogenesis. When the update frequency was not high enough, structural damage to the small scale upper-air trough was found in the relaxation zone. In a follow-up study, Gustafsson et al. (1998) showed that errors in the initial and lateral boundary data could explain two February 1995 events that were poorly forecasted by the operational HIRLAM model.

The impact of LBC update times has been found in other models as well. Termonia (2003) found that the ALADIN 
regional model (ALADIN International Team (1997)) required an update frequency of one hour to forecast Storm Lothar $^{1}$ with similar quality to the forcing data from ALADIN-France. Termonia et al. (2009) observed that the errors introduced due to the temporal interpolation of infrequent LBC data led to a reduced pressure drop of another storm in the ALADIN model.

In addition to an increased update frequency, Chikhar and Gauthier (2017) found that the use of spectral nudging could lead to a significant reduction of the temperature bias in the fifth generation Canadian Regional Climate Model (CRCM5). They also found that neither an increased model domain nor an increased blending zone (Davies relaxation zone) were able to correct these biases. While they found significant improvement when increasing the LBC update frequency from 6-hourly to hourly, additional increase to sub-hourly resolution had limited effect.

While the earlier studies focused on how LBC interpolation can impact the forecast skill of individual storms, these effects also impact other types of investigations, for example, storm climatology studies like Larsén et al. (2017a). In studies like Larsén et al. (2019), which focuses on the estimation of extreme offshore wind speeds, correctly simulating both the intensity and location of hundreds of storms is crucial for reliable statistics. Therefore, careful design of the LAM settings is required. Larsén et al. (2017a) points out the importance of domain size, horizontal resolution, initialisation, and simulation time on model results. However, another challenge was identified, that of storms entering through the corner of the model domain rather than through an edge, which leads to a lack of storm intensification and can have large track errors. This was initially identified during a domain evaluation study using the Weather Research and Forecasting (WRF, Skamarock et al. (2008)) model in Imberger (2017), which was carried out within the framework of the above mentioned storm climatology over the North Sea (Larsén et al. (2017a)). Imberger (2017) tested different WRF domain setups and found a lack of expected storm development, in terms of both deepening and track, compared to forcing data and the best track data provided by the Extreme Wind Storms Catalogue (XWS, Roberts et al. (2014)) for a particular case, where the storm centre entered the domain very close to its south-western corner. This issue will be further referred to as the "corner issue" and described in more details in Section 2. This study builds upon and extends the initial findings in Imberger (2017) by addressing the following questions: (1) how does the "corner issue" influence large structures on the order of several hundred kilometres, such as the area of decreased

\footnotetext{
${ }^{1}$ Referred to as "French Christmas storm" in Termonia (2003)
} 
57 sea level pressure (SLP) and the horizontal wind fields, and (2) to what extent can commonly applied methods for modifying the LBC introduction improve the LAM model results regarding storm intensity and path.

Four methods are evaluated in this study, domain displacement, nudging techniques, adjustment of the relaxation layer, and increased LBC update frequency, which will be described in more detail in Section 3. The paper is laid out as follows: A more thorough introduction to the "corner issue" is given in Section 2; The general model setup and all investigated model scenarios are presented in Section 3; Section 4 describes the evaluation methods including a description of measurements, key time-periods and the best storm track data used for validation. The results are presented in Section 5, and key findings are discussed in Section 6. The paper finalises with conclusions in Section 7.

\section{2 | THE "CORNER ISSUE"}

The "corner issue" refers to the distorted introduction of the large-scale structure of a mid-latitude storm when the storm centre is located too close to the lateral boundary corner of the LAM. One example of a domain setup suffering from the "corner issue" would be the domain setup "REF", in Figure 1, for the simulation of storm "Christian". The cyclone centre passes through the south-west corner of the boundary region and, as the model integration continues,

combination of spatial and temporal interpolation and model relaxation in the buffer zone of the LAM domain acts on the large-scale structure from two different directions. In the storm case investigated by Imberger (2017), this resulted in a lack of expected storm deepening and storm track deviation from forcing data and XWS best track data. It was also shown that shifting the domain southward, ("REF-South" in Figure 1) to avoid the "corner issue", improves the intensification of the simulated storm. The reduced pressure drop due to the "corner issue", seen with storm "Christian", was also found for two other storm cases in the XWS catalogue (storm "Ulli" and storm "Patrick", not shown). This suggests that the "corner issue" is not, in principal, related to the structure of a particular storm, but a more general issue. However, in this study, we focus on a single storm, to allow for more sensitivity studies to be performed.

"Christian" was chosen as the example, because (1) it was a failed case in the storm climatology created by Larsén 
80

81 a typical storm within the area covered by the XWS catalogue. When compared to the full list of storms in the XWS

82 catalogue, "Christian's" lowest minimum sea level pressure and highest maximum wind speed are quite representative for the listed storms (Figure 2), making it well suited for a case study. "Christian" was a Hurricane-force 12 European wind storm that impacted several European countries during October 2013 on its path from the North Atlantic toward the Baltic Sea. The name "Christian" follows the designation from the Free University Berlin, as all storm names in this publication do, but other names have been used by different institutions: "St. Jude" (UK MetOffice), "Simone" (Swedish Meteorological and Hydrological Institute) and "Oktoberstormen/Allan" (Danish Meteorological Institute). "Christian" originated as a secondary low to the south of the Icelandic Low "Burkhard" on 26 October. It was characterised as a rapidly moving storm with landfall in the region of Cornwall on 2200 UTC 27 October 2013 (Haeseler and Lefebvre (2013)). The highest intensity of the storm based on minimum SLP and maximum 850 hPa relative vorticity was reached on 28 October 2013 (cf. XWS Catalogue (cited 2019)). Additional information about the storm track and atmospheric parameters of "Christian" are summarised in the XWS Catalogue (cited 2019) and AIR Worldwide (cited 2018), while Hewson et al. (2014) provides a comprehensive description of its meteorological characteristics.

\section{MODEL SETUP}

In this section, the model setups will be described. First in Section 3.1 the basic setup of the model, which is consistent across most of the simulations, will be introduced. Then in Section 3.2 the different sensitivity studies will be described.

\section{1 | Basic Model Setup}

The limited area model used in this investigation is version 3.7.1 of the non-hydrostatic Advanced Weather Research and Forecasting Model (WRF, Skamarock et al. (2008)) using the ARW core and terrain-following vertical coordinate. 
Figure 1 (solid orange frame) shows the domain used for most of the simulations, "REF", which has a spatial extent of $2700 \mathrm{~km} \times 1800 \mathrm{~km}$ and a horizontal resolution of $18 \mathrm{~km}$, leading to a domain that consists of $150 \times 100$ grid points. No nested domains were used, since the focus was on the impact of LBCs from a global model. There are 52 levels in the vertical.

LBCs are introduced into the WRF model through a Davies relaxation zone. The relaxation zone consists of a number of grid cells inside the LAM domain where relaxation towards spatially and temporally interpolated largescale forcing data takes place. In this zone, the update of prognostic variables is determined based on the difference between the large-scale forcing value and the LAM model value (Davies and Turner (1977)). The weight of the largescale data decreases with the distance from the domain border. The weight is calculated using two weighting functions $F_{1}(n)$ and $F_{2}(n)$ and a 5-point horizontal smoother (see Skamarock et al. (2008) for details). The weighting functions are defined as:

$$
\begin{aligned}
F_{1}(n) & =\frac{1}{10 \Delta t} \frac{1+N_{r}-n}{N_{r}-1} \\
F_{2}(n) & =\frac{1}{50 \Delta t} \frac{1+N_{r}-n}{N_{r}-1} \\
2 & \leq n \leq N_{r},
\end{aligned}
$$

where $n$ is the position from the border, $N_{r}=N_{\text {relax }}+1$ is the total Davies relaxation zone width, $N_{\text {relax }}$ is the pure relaxation zone width, and $\Delta t$ is the integration time step, which was set to $37.5 \mathrm{~s}$ in this study. By default, the WRF model has $N_{\text {relax }}=4$. Given the Davies relaxation zone, two LAM border areas can be defined, namely a "hard" and a "soft" border. The "hard" border is what we typically think of as the extent of the domain, while the "soft" border is located at the edge of the relaxation zone, where the LAM physics are fully in control of the solution.

The total simulation time, which is the same for all simulations, is set to 36 hours (1200 UTC 26 October 2013 to 0000 UTC 28 October 2013). Included in the total simulation time is a 12 hour spin-up period, which allowed a sufficient build up of the kinetic energy in higher model levels, based on the kinetic energy spectrum (not shown). The storm centre enters the WRF domain 24 hours after initialisation, allowing for the investigation of model results both 
before and after the introduction of the storm. If not stated otherwise, LBCs are updated every 6 hours using data from the 6 hour forecast of the previous initialisation of the Climate Forecast System Version 2 Forecast (CFSv2; see Saha et al. (2014) for the publication and Saha et al. (2011) for the data set). The 6 hour window is used by default as this is a common update frequency. The spatial resolution of CFSv2 is 0.2 degrees for surface fields and 0.5 degrees for variables provided on the vertical pressure levels. LBCs between two subsequent forcing data fields needed by the LAM are obtained by linear interpolation to the integration time step (here $37.5 \mathrm{~s}$ ) of the model (WRF default).

Micro-physics are parameterised with the New Thompson enhanced bulk scheme (Thompson et al. (2008)) and cloud fractions for micro-physics clouds are activated and follow Xu and Randall (1996). To parameterise convective processes under this horizontal resolution, the Kain-Fritsch parameterisation scheme (Kain (2004)) is activated and the calling period is set to 5 minutes. Long- and shortwave radiation are calculated by the RRTMG scheme as described in lacono et al. (2008) and called every $18 \mathrm{~min}$, following the recommendation in Dudhia (2017). The Unified Noah land surface model (Tewari et al. (2004)) with four soil levels is chosen to represent the land surface while land usage is obtained from the U.S Geological Survey (USGS, 24 land use categories). The Level 3 Mellor-Yamada-NakanishiNiino (MYNN, Nakanishi and Niino (2006)) scheme is used to model surface and planetary boundary layer (PBL). This physics configuration follows the setup used in Larsén et al. (2017b) and Larsén et al. (2019), which showed good performance when simulating storms events. Sea surface temperature is not updated during the simulation. A surnmary of the model specifications can be found in Table 1.

\subsection{Sensitivity Studies}

This section describes the different perturbations to the reference model setup described in Section 3.1 to investigate the issues related to the introduction of "Christian" into the WRF LAM domain. All methods in this study were carried out using the available capabilities of the WRF model environment, allowing for easy implementation in other studies. The simulation naming convention and a short description of case study characteristics is provided in Table 2 . These studies can be sorted in four main categories: 
- $\quad$ Displacement of the model domain (Section 3.2.1)

- The use of spectral nudging (Section 3.2.2),

- $\quad$ Relaxation zone adjustments of the WRF domain (Section 3.2.3),

- $\quad$ Adjustments of temporal update frequency of the lateral boundary conditions (Section 3.2.4).

The first method relies on a modification to the static WRF domain (shifting), but the other three investigations can be applied without changing the WRF model domain.

If not stated otherwise, model parameters are identical to the parameters for the reference simulation (cf. Table 1).

\subsubsection{Domain Displacement Method}

In this sensitivity study, a simple displacement of the model domain is applied, allowing the storm structure to be introduced closer to the centre of the western edge. This is shown in Figure 1 where the solid orange frame is the original domain ("REF"). The dashed line in the figure depicts an identical domain that has been shifted to the south ("REF-South").

\subsection{2 | Spectral Nudging Method}

Termonia (2003) showed that the worst performance for the linear interpolation of the LBCs of storms occurs when the storm is fully outside of the domain at one LBC update time-step and at the next time-step it is fully inside the domain. By adding nudging to the LAM, the information about the storm can be added to the interior of the model even though it was not added through the boundaries. For this study, the the spectral nudging technique (Waldron et al. (1996), von Storch et al. (2000)) was used. The key idea of spectral nudging is that nudging should only act on coarse scales, determined by a specified wave number threshold. Spectral nudging is widely used since it can reduce the sensitivity of the model solution to domain geometry, like the domain placement on earth (see Miguez-Macho 
et al. (2004)).

The implementation of spectral nudging in WRF is based on the formulation in the Regional Atmospheric Modeling System (RAMS) by Miguez-Macho et al. (2004) and can be described as stated in Equation 2 (Gómez and MiguezMacho (2017)):

$$
\frac{\partial \alpha}{\partial t}=F(\alpha, \vec{x}, t)+G_{\alpha} W(\vec{x}, t) V(z) \text { Filt }_{x y}\left[\left(\hat{\alpha}_{0}-\alpha\right)\right]
$$

The notation is based on Gómez and Miguez-Macho (2017) with the following definitions: $\alpha$ is a generic placeholder 2 for any model state variable and $\hat{\alpha_{0}}$ describes the target value for the nudging procedure, which comes in this case from the forcing data. $F$ describes the tendency term determined by the model at a specific time $t$ and place $\vec{x}$ and $G_{\alpha}$ represents the nudging strength. $W$ and $V$ are time-dependent weight factor and vertical weight factor respectively. Filt $x y$ represents the filtering algorithm applied to $\left(\hat{\alpha_{0}}-\alpha\right)$. Filtering is first performed row-wise and then repeated column-wise, for each row/column in $\left(\hat{\alpha_{0}}-\alpha\right)$. The nudging is carried out using the following steps: (1) transformation to spectral space via Fast Fourier Transformation (FFT), (2) zeroing out signal amplitude for wavelengths smaller than the cut-off wavelength, (3) back-transformation via Inverse FFT (Gómez and Miguez-Macho (2017)). This means that wavelengths larger than the threshold will remain in the nudging data, while smaller wavelengths will be filtered out. For further details, the reader is referred to Gómez and Miguez-Macho (2017), which provides a comprehensive description of the implementation of spectral nudging in WRF.

In the current study, spectral nudging towards the forcing data for higher wavelengths was applied to the following list of governing variables: grid-relative wind components $(U, V)$, potential temperature $(\theta)$, and geopotential height $(\phi)$. A constant nudging strength $G_{\alpha}$ of $0.0003 \mathrm{~s}^{-1}$ following the default value in Skamarock et al. (2008) is used. In the WRF model, spectral nudging is controlled by two parameters, the nudging strength and the nudging range. The nudging strength (weak/strong) defines how strongly the LAM is nudged toward the nudging data, and the nudging range (narrow/wide) defines the range of wavelengths that are affected by the nudging. Two nudging ranges were investigated in this study, corresponding to nudging waves larger than $900 \mathrm{~km}$ ("NUD900km") and larger than $100 \mathrm{~km}$ 
("NUD100km"). When the cyclone enters the WRF domain (1200 UTC 27 October 2013), its west-east extension is approximately $200 \mathrm{~km}$, based on the largest closed isobar in the CFSv2 data. It should be noted that the effective resolution of WRF in this study is approximately $126 \mathrm{~km}$, based on the expected $7 \Delta x$ resolution of WRF (Skamarock (2004)), meaning that effectively all resolvable wave lengths in the outermost domain are affected by the spectral nudging term in the "NUD100km" study. This suggests that for "NUD100km", spectral nudging acts similarly to grid nudging (Stauffer and Seaman (1990)), which adds a nudging term to all wavelengths. For both simulations, nudging is active in the whole domain and over the whole simulation period (i.e. $W(\vec{x}, t) \equiv 1$ ), but only above the planetary boundary layer (i.e. $V(z)=1$ for heights above the PBL, zero otherwise).

\subsection{3 | Relaxation Zone Adjustment}

The thickness of the Davies relaxation zone should have an impact on the introduction of a system such as "Christian" to the LAM. To investigate the behaviour of the storm when changing the relaxation zone width, two setups were investigated. The first reduces the relaxation zone width to $N_{r e / a x}=2$ grid cells ("HalfRelaxZone"), while the second uses twice the default width, i.e. $N_{\text {relax }}=8$ grid cells ("2xRelaxZone").

\subsubsection{Increased LBC Update Frequency}

Several studies have shown the impact of increased LBC update frequency on the introduction of storms into a LAM. In this study, two simulations were tested that utilised additional forecasts from the CFSv2. Both 3-hourly update ("CFSv2-3h") and hourly update ("CFSv2-1h") frequencies were examined. This is inspired by commonly investigated update frequencies (see e.g. Tudor and Termonia (2010), Matte et al. (2017)) and used intervals in operational models (e.g. Consortium for Small Scale Modeling (COSMO) (cited 2018)). Due to the unique setup of the CFSv2 simulation, where each forecast is only 6 hours long, the hourly forecast period is represented as follows, the initial fields are from the 6 hour forecast of the simulation started at 0600 UTC 26 October 2013, then the next six hours are forecast hours 1-6 of the simulation started at 1200 UTC, and continuing in six hour windows until the end of the study. 


\section{4 | TOOLS AND PRODUCTS USED FOR MODEL EVALUATION}

The different simulation setups described in Section 3.2 are evaluated using comparisons with buoy observations, investigations of snap-shots at times of interest, and deviation from the Extreme Wind Storms catalogue.

\section{1 | Buoy Observations}

The coarse resolution of the modelled data limits a quantitative comparison of wind speed and direction using point measurements, due to the resolution mismatch. Therefore, the values of wind speed magnitude will be considered qualitatively. However, SLP is less sensitive to the resolution mismatch, and therefore, can be evaluated quantitatively. For this study, buoy measurements from the European Marine Observation and Data Network (EMODnet, cited 2018) are used to perform these evaluations, which provides observations of a collection of oceanic and meteorological variables.

Initially all relevant buoy data, inside the WRF domain and available at the top of the hour, to match the output time of WRF, within simulation time between 0000 UTC 27 October 2013 and 0000 UTC 28 October 2013 are selected, along with 6 hours before and after the WRF simulation time to study additional trends in the measurements. The data set is then filtered to remove data flagged with quality issues. This results in a collection of 12 stations used in the analysis. The locations of the buoy measurements will be shown later in Section 5.6. The model SLP is reconstructed from the WRF output parameters geopotential height, temperature, pressure, and water vapour mixing ratio, using the wrf_slp function, which is part of the WRFUserARW.ncl library in the NCAR Command Language (NCL,UCAR/NCAR/CISL/TDD (2017)). Model and observed SLP are compared by using the closest model grid point to each buoy location. 


\section{2 | Investigated Time Stamps}

Two snap-shots were used to investigate the spatial behaviour of the storm, 1800 UTC 27 October 2013 and 0000 UTC 28 October 2013. These were selected for a few different reasons: (1) the entire storm was located inside the mesoscale model domain, (2) the model had enough time to develop its own features and (3) there are available buoy measurements over a wide spatial range, including close to the storm centre.

For temporal analyses, the entire simulation period, excluding spin-up time, (0000 UTC 27 October 2013 to O000 UTC 28 October 2013) is used to compare the different simulations.

\subsection{Storm Track Data from Extreme Wind Storms (XWS) Catalogue}

The Extreme Wind Storms (XWS) Catalogue is a database of 52 European windstorms covering the time period from 1979 to 2013 (see Roberts et al. (2014) for the article and XWS Catalogue (cited 2019) for the data set). The catalogue contains two sets of storm tracks, one based on minimum mean SLP and the other on the maximum relative vorticity at $850 \mathrm{hPa}$, and 3-second gust footprints (raw data set and re-calibrated) for each storm. The footprints are defined by the maximum 3-second gust over a $72 \mathrm{~h}$ period at a certain location. A detailed overview of the methodology behind the XWS data set is given in Roberts et al. (2014). Within the scope of the current investigation, the storm track data of cyclone "Christian", based on minimum SLP, is used for examining the model results. The track data provides the position of the local minimum sea level pressure (LMSLP) every 3 hours, and is obtained from a regional dynamically downscaled version of the ERA-Interim (Dee et al. (2011)) data set using the methodology described in Hoskins and Hodges (2002)

\section{5 | RESULTS}

The results are presented in six parts. First, the storm intensification and LMSLP location of each of the different simulations is presented and compared to CFSv2 and XWS in Section 5.1. Then, Section 5.2 shows the results of the 
simple domain shift method, while Section 5.3 to Section 5.5 show the results from domain independent methods to tackle the "corner issue". Finally, Section 5.6 presents a spatial and temporal comparison of the different simulations with buoy data. The data obtained from the forcing data CFSv2 and from "REF-South" are clipped to the reference domain.

\subsection{Storm Intensification Compared to CFSv2 and XWS}

Table 3 summarises the magnitudes in LMSLP, for each of the WRF simulations, as well as, the CFSv2 forcing data and the XWS catalogue at 1800 UTC 27 October 2013 (30 hours after model initialisation) and 0000 UTC 28 October 2013 (36 hours after model initialisation). The storm intensity is quantified using the LMSLP of the storm centre. "CFSv2-1h" is the only simulation that provides LMSLP more than $3 \mathrm{hPa}$ below the forcing data estimation at both $30 \mathrm{~h}$ and $36 \mathrm{~h}$ after model initialisation. "CFSv2-3h" and "REF-South" have a LMSLP value more than $3 \mathrm{hPa}$ below the forcing data $36 \mathrm{~h}$ after initialisation. Furthermore, it can be seen that CFSv2 and XWS agree quite well in terms of the storm intensity based on minimum SLP.

Table 4 and Table 5 compare the simulated storm centre locations, and their distances to XWS and CFSv2 at 1800 UTC 27 October 2013 and 0000 UTC 28 October 2013, respectively. With respect to the storm centre location, a difference of $130 \mathrm{~km}$ is found between the XWS and CFSv2 location at 1800 UTC 27 October 2013 and $220 \mathrm{~km}$ at 0000 UTC 28 October 2013. This is comparable to the cyclones west-east extension when it enters the WRF domain (1200 UTC 27 October 2013), which is on the order of $200 \mathrm{~km}$ or three to four CFSv2 grid points (0.5 degree spatial resolution). The distance between the WRF storm centre and that of the CFSv2 is always less than the distance between the CFSv2 and the XWS (except for "REF" at 0000 UTC 28 October 2013). However, this value varies quite significantly depending on the simulation setup. 


\section{2 | Reference Case and Effect of Domain Displacement}

There are major differences in the development of the storm with the default domain ("REF") and the shifted domain ("REF-South", Figure 1). Both the storm intensity and position are affected by the domain shift. This can be seen best in the SLP field in Figure 3. At 0000 UTC 28 October 2013, "REF" (Figure 3d) develops a small decrease in SLP down to 986 hPa centred north of Cornwall, while "REF-South" (Figure 3f) shows a much stronger decrease in SLP of $981 \mathrm{hPa}$ and a different location of the storm centre, which is over south Wales. The CFSv2 had an intensity of $984 \mathrm{hPa}$, which is actually lower than the "REF" case (cf. Table 3). This strongly indicates a misinterpretation of the forcing data at the lateral boundary corner in "REF". While a higher storm intensification is expected in the higher LAM domain resolution, the storm intensification in "REF" is not present and the LMSLP is higher than estimated by CFSv2. Furthermore, the storm centre (based on the location of the LMSLP) is displaced compared to the forcing data (compare Figure 3b). "REF-South" also simulates the storm centre much closer to the forcing data (30 km, see Table 5) than "REF" (160 km, see Table 5). The differences in the simulation are seen when the storm enters the domain approximately at 1200 UTC 27 October 2013 (left-column of Figure 3), which suggests differences in how the storm is introduced to the LAM model. The differences obtained by the simple domain shift also suggest that more general effects like potential inconsistencies between CFSv2 and WRF physics or spin-up time are not the dominant factor the distortion, since they would be identical in both situations.

Figure 4a to Figure 4c show the wind speed at 850 hPa on 0000 UTC 28 October 2013 for CFSv2, "REF", and "REF-South". The greatest difference between the two WRF simulations can be seen in the regions of low wind speeds, below $10 \mathrm{~m} \mathrm{~s}^{-1}$. In "REF-South" and CFSv2, this region is located near Cardiff and extending to the northeast, while in "REF" it is found off the coast of Pembrokshire to the south-west of the other simulations. Differences in the high wind speed region, above $35 \mathrm{~m} \mathrm{~s}^{-1}$, and large-scale flow direction are similar in all simulations. While the difference between the maximum wind speed at $850 \mathrm{hPa}$ of "REF" $\left(V_{\max , R E F}=40.2 \mathrm{~m} \mathrm{~s}^{-1}\right)$ and "REF-South" $\left(V_{\max , R E F-S o u t h}=40.5 \mathrm{~m} \mathrm{~s}^{-1}\right)$ is marginal, both simulations underestimate the maximum wind speed obtained from CFSv2 by around $3 \mathrm{~m} \mathrm{~s}^{-1}\left(V_{\max , C F S v 2}=43.0 \mathrm{~m} \mathrm{~s}^{-1}\right)$. Regarding the location of the high wind speed zone, "REF" is in closer agreement with the forcing data, while "REF-South" shows an extension of the high wind speed north of $52^{\circ} \mathrm{N}$ 
over England.

\section{3 | Effect of Spectral Nudging}

There are large changes to the SLP field when applying the spectral nudging technique (Figure 5). In the "NUD100km" simulation, the storm centre has shifted to the north-east, when compared with "REF". Additionally, the deepening of the storm to the north of Cornwall, which was found in "REF", is not present in "NUD100km". The nudging also created blurring effects, resulting in a spreading of the low SLP field around the storm, compared to the "REF-South" and CFSv2 simulations, and a large region of moderately lower SLP than in "REF". However, "NUD100km" does a similar job of estimating the location of the storm when compared with "REF-South" and CFSv2 (see Table 5).

The higher wavelength range of "NUD900km" leads to a slightly higher SLP across most of the domain, but overall negligible differences are found in comparison with "NUD100km" (not shown). A third spectral nudging study, that extended the nudging to model layers in the PBL, did not show significant effects in the sea level pressure field either (not shown). Based on these results, spectral nudging did not improve the forecast of "Christian" as much as moving the domain did in "REF-South".

When investigating the wind speed field at $850 \mathrm{hPa}$ (Figure 4d), it is easy to see the effect of the spectral nudging Lr $\mathrm{m}$ on the wind speed components $U$ and $V$. The regions of low and high wind speeds are close to the shape and location of the corresponding regions in the CFSv2 data set (Figure 4a). The large extension of the low wind speed region in southwest-northeast direction is maintained in the simulation while this feature is not present in "REF-South". It must be emphasised that the wind speed components $U$ and $V$ are directly influenced by the spectral nudging term while SLP is not. This explains the stronger effect on the wind speed field while the SLP field is less affected.

\section{4 | Effect of Relaxation Zone Adjustments}

Figure 6 shows the SLP field for the simulations with adjusted Davies relaxation zone width. The relaxation zone width has a significant impact on the storm intensification in this particular case, likely due to the storm entering close 
to the corner of the domain. The results of "2xRelaxZone" do not show a significant decrease in SLP, but actually a strong increase in SLP over Cornwall. In "HalfRelaxZone", there is a decrease in SLP around the storm centre from CFSv2, however, the increase in the storm intensity is still smaller than in "REF-South", and the location of the storm centre is between that of "REF" and "REF-South" (cf. Table 5).

Some of the reasons for these differences can be seen by looking at the $850 \mathrm{hPa}$ relative vorticity field (Figure 7). In all four simulations, an artificial pattern can be seen near the south-west corner of the relaxation zone, which runs parallel to the "soft" border of the relaxation zone. While similar patterns are visible in all four simulations, the width of the relaxation zone effects how far into the domain the distortion is found. Additionally, by extending the "soft" border of the relaxation zone further into the domain, and thereby, closer to the area of interest, additional spatial blur and distortion of the horizontal fields occurs.

Tudor and Termonia (2010) found that a very wide relaxation zone could cause features to bounce back into the domain, rather than leave as they should. This issue was investigated here, but no such behaviour was found in either the SLP field or the relative vorticity field at $850 \mathrm{hPa}$ (not shown).

\section{. \\ 5.5 | Effect of LBC Update Frequency}

FIgure 8 shows the SLP results from the "CFSv2-3h" (Figure 8a) and "CFSv2-1h" (Figure 8b) simulations at 0000 UTC

28 October 2013. The simulations with higher update frequency show a major decrease in SLP compared to "REF", which is more pronounced in "CFSv2-1h" than "CFSv2-3h". The impact can be seen more clearly in the SLP difference compared to "REF", with lower SLP across most of the domain in the higher frequency simulations. The largest SLP differences, between $5 \mathrm{hPa}$ and $8 \mathrm{hPa}$, are located to the north-east of the CFSv2 storm centre in both "CFSv2-3h"

(Figure 8c) and "CFSv2-1h" (Figure 8d). LMSLP values as low as 981 hPa ("CFSv2-3h") and 979 hPa ("CFSv2-1h") are seen.

The increased storm intensity in "CFSv2-1h" can also be seen in the $850 \mathrm{hPa}$ wind speed field (Figure 4f). The highest wind speeds found in "CFSv2-1h", maximum wind speed of $V_{\max , C F S v 2-1 \mathrm{~h}}=44.5 \mathrm{~m} \mathrm{~s}^{-1}$, compared to "CFSv2-3h", maximum wind speed of $V_{\max , C F S v 2-3 h}=42.8 \mathrm{~m} \mathrm{~s}^{-1}$, and the original CFSv2 data $\left(V_{\max , C F S v 2}=43.0 \mathrm{~m} \mathrm{~s}^{-1}\right)$ in the 
high wind speed region. In "CFSv2-3h" (Figure 4e), the wind speed is not increased compared to the original CFSv2 data set (Figure 4a). In the low wind region, to the north of the storm, the changes to the wind speed and large-scale flow direction are not as pronounced. The low wind region in "CFSv2-1h" is located slightly further north-east.

\section{6 | Spatial and Temporal Distribution}

The measured and simulated SLP are compared at the 12 buoys selected using the process described in Section 4.1

at both snap-shot times (Figure 9). The results are sorted by distance to the CFSv2 storm centre, to evaluate its relationship to model performance. We find that there is a relationship between the distance to the storm centre and the spread of the simulation results. Locations close to the CFSv2 storm centre, within approximately $400 \mathrm{~km}$, show significant differences, but the results are consistent in areas further from the storm centre. Although stations \#34 and \#35 have large differences even though they are located far from the storm centre in all scenarios at both times.

The buoy data was also used to evaluate the performance of the different model simulations across the entire time of the simulation. The temporal dimension plays an important role in the model evaluation, as seen in the spatial plots of the SLP field across the different simulations. The SLP time-series at all 12 buoy locations were compared with the simulation, however only four locations were focused on for this report (Figure 10). The four locations were selected for the following reasons: buoy station \#17 was close enough to the storm travel path to be impacted in both simulation and measurements; buoy station \#34 was far from the storm track of cyclone "Christian", allowing for the investigation of model performance far from the storm; buoy station \#10 was located east of the storm travel path, allowing the investigation of the front-side of the storm; and buoy station \#19 was picked due to its location in the English Channel, which was identified as a region of large wind speed changes using the XWS storm footprint.

The time-series plots allow for the investigation of general SLP trends and the timing of the minimum SLP for a given location in both the simulations and measurements. At buoy station \#17, both the drop in SLP due to the passing storm centre and the subsequent recovery of SLP after the storm passed the buoy can be seen clearly in both the measurements and all the models. However, while the general trend is followed in all simulations, only "CFSv2-1h" and "CFSv2-3h" capture the timing and magnitude of the SLP drop around 1700 UTC 27 October 2013. 
All other configurations have a time shift of around one hour. At buoy station \#10, which is passed by the storm at a later time, all of the models show a phase shift of around two hours, and while "CFSv2-1h" and "CFSv2-3h" have larger pressure drops than the other models, the drop is still smaller than the observed value. This phase shift is not as obvious at buoy station \#19, which is around $230 \mathrm{~km}$ further east than station \#10, but only "CFSv2-1h" and "CFSv2-3h" capture the magnitudes of the pressure well. Further away from the storm centre, at buoy station \#34, there are still significant differences in the SLP estimation across the different simulations. The simulations with high update frequencies ("CFSv2-1h", "CFSv2-3h") and the heavily nudged simulation ("NUD100km") are closer to the measurements than the other simulations especially in the region of low SLP around 0800 UTC 27 October 2013 before the storm enters the domain. This could be related to the impact of another very strong depression, referred as "Burkhard" in e.g. Haeseler and Lefebvre (2013), which was located close to buoy station \#34, see also Section 2.

\section{6 | DISCUSSION}

While the proper introduction of the large-scale structures via the boundaries of a LAM is generally important, the "corner issue" reveals that boundary corners are especially vulnerable when complex large-scale structures like mid1'tude storms are involved. Shifting the domain so that the storm does not enter at the corner of the domain (i.e. avoiding the "corner issue") was found to improve the simulation of both the storm intensity and location. This highlights that the introduction at the boundary corner is a particular challenge that might not be experienced under normal conditions (i.e. introduction via the edge of the domain). Domain shift investigations of the other storm cases mentioned earlier (storm "Ulli" and storm "Patrick") revealed the same effect of improved storm intensification with respect to the sea level pressure field (not shown). This emphasises that the lack of storm intensification as a consequence of the "corner issue" is not unique to a specific storm type.

Four different methods for introducing a typical mid-latitude storm into the WRF LAM were investigated and evaluated spatially and temporally using the forcing data, external storm track data, and buoy observations with a focus on limiting the "corner issue's" impact. Of the three approaches using fixed domains, only the increased LBC 
update frequency improved the simulation compared to the large scale forcing data. This points out that the main driver in conserving the large-scale structures in this case is the proper import of the forcing data via LBCs which can achieved best by either a domain shift, if possible, or an increased LBC update frequency. This enables the LAM to conserve the large-scale structures and allows for the development of smaller-scale features that were not present in the forcing data, but are associated with the storm. While a direct usage of the forcing data would avoid the issue of lateral boundaries and the "corner issue" completely, the coarse resolution and lack of small scale information limits its use for studying meteorological parameters that rely on well resolved small-scale patterns, like wind speed. Changes to the introduction of the LBCs influences the storm location and size, while smoothing influences localised features, such as the intensification of the storm centre.

An inherent problem of avoiding the "corner issue" by domain shifting is the question of how much shifting is sufficient, which likely varies depending on the size of the storm. Furthermore, moving the domain is often not an option. For example, when running forecasts and climatologies, the domain needs to be fixed to ensure consistency and allow for automation of the study, i.e. not every case can be focused on as a case study. Therefore, three approaches, which do not involve moving the domain, were investigated: spectral nudging, relaxation zone adjustments, and changes to the LBC update frequency.

Spectral nudging was investigated because it constrains the LAM to maintain the large-scale information provided by the forcing data, without limiting the LAMs ability to build up the smaller scales. While it was able to correct the storm location compared to the "corner issue" affected simulation, it also introduced spatial blurring/smoothing effects which prevented the expected intensification of the storm in the WRF simulation (Figure 5). Similar effects were also found in Alexandru et al. (2009), who observed a reduction in the spectral power of the vorticity field when performing large-scale spectral nudging using the Canadian RCM (CRCM). This reduction could be associated with decreased cyclone intensities (Alexandru et al. (2009)). This highlights one difference when evaluating simulation setups for mean state investigations and for extreme events. LAM studies of mean state behaviour aim to add local information that should not significantly alter the large-scale flow, and therefore, nudging the model toward the forcing data can be beneficial. However, LAM studies of extreme events, such as storms, require the retention of small scale structures that enhance the large scale flow, which standard nudging techniques will often smooth out, by nudging 
towards the forcing data. This is because, nudging reinforces the mean state behaviour, which can be useful for longterm mean climate studies, but must be used with care when focusing on extreme events, such as storms. Spectral nudging seeks to limit the smoothing of small scale features through its wave-length cutoff. The cutoff wavelength should be based on the reliability of the large scale forcing data. While the CFSv2 forecast product used as forcing data is provided every 0.5 degrees, the spectral atmospheric model behind the forecast product has a triangular truncation of T126 (Saha et al. (2014)), which is equivalent to approximately $100 \mathrm{~km}$ (Saha et al. (2014)). Based on this estimate, sufficiently resolved scales are only expected for wavelengths larger than $100 \mathrm{~km}$, which makes "NUD100km" a fringe case until which spectral nudging would be meaningful. "NUD900km" improved the storm's location compared to "REF" (without nudging), suggesting that scales larger than $900 \mathrm{~km}$ are crucial for improving the storm location in this case. The only marginal differences seen between "NUD900km" and "NUD100km" with respect to the storm intensification indicate that the LAM still fails to build up crucial structures responsible for the storm deepening beyond what is already present in the forcing data when faced with the "corner issue".

Since the "corner issue" is related to the passing of a feature through the boundary of the model, adjustments to the lateral boundary relaxation zone have an impact on this process. Similar to spectral nudging, the relaxation zone generates spatial smoothing, but in this case only in an area next to the lateral boundary. By increasing the relaxation zone's width, it is possible to introduce the storm structure more gradually. By reducing the relaxation zone's width, possible to concentrate the forcing on a small band close to the boundary. This results in less smoothing/blurring in the interior of the model domain and higher storm intensification (cf. Figure 6d, Table 3). Spatial smoothing due to the relaxation zone is especially relevant in the context of the "corner issue" because the number of relaxation zone cells in the LBC boundary corner is affected by the relaxation zone layers from both adjacent edges. A doubling of the relaxation zone width from $N_{\text {relax }}=4$ (default) to $N_{\text {relax }}=8$ will double the relaxation zone layers at each adjacent edge, quadrupling the number of overlapping relaxation zone cells in the corner area. This significantly increases the number of cells where model relaxation in the boundary corner can take place.

The relaxation zone sensitivity analysis highlights also another challenge in connection with the relaxation, namely the presence of non-physical features as for example seen in the relative vorticity field along the southern "soft" border (Figure 7). These features were present in all simulations, but can be seen clearest in "2xRelaxZone". While 
the presence of perturbations within the relaxation zone is observed also under normal conditions (see e.g. Warner et al. (1997), Davies (2014)), structures close to the LAM corner are especially vulnerable due to relaxation of the forcing data from two sides. This suggest that both the "hard" and "soft" borders need to be taken into account when introducing large scale features close to the lateral boundary corner. These effects turned out to be most problematic in "2xRelaxZone", since the increased relaxation zone width brought the affected area closer to the area of interest.

Increasing the temporal frequency of the LBCs was found to improve the introduction of the storm, and reduce the smoothing effects. Only the "REF-South" simulation had an SLP drop of similar magnitude to "CFSv2-3h" and "CFSv2-1h", but in "REF-South", significant storm deepening did not occur until 36 hours into the simulation. Both the location of the storm centre and the storm intensity are closer to the expected results obtained from "REF-South" when using the higher frequency LBC updates. The improvement seen in simulations with increased LBC update frequency is in line with previous studies such as Gustafsson (1990), Termonia (2003) and Termonia et al. (2009). In the case of "Christian", its fast movement further favours the use of high frequency LBC updates. The travel speed of the storm, in the time period of interest, is approximately $95 \mathrm{~km} \mathrm{~h}^{-1}$, based on comparing the CFSv2 LMSLP locations in Table 4 and Table 5. Using the storm locations from the XWS data set suggests a travelling speed of $80 \mathrm{~km} \mathrm{~h}^{-1}$. At $95 \mathrm{~km} \mathrm{~h}^{-1}$, the storm would move approximately $570 \mathrm{~km}$ in the 6-hours between LBC updates in the default case. This is equivalent to approximately $32 \Delta x$, and approximately three times the storm size based on the estimation in Section Accordingly, it is a challenge for the LAM to develop the necessary small-scale structures, since the system passes the model domain so quickly, not allowing the time necessary for the model to adjust to the new large-scale features. When storm locations and distances are evaluated, the origin of the data sets must be kept in mind. Both CFSv2 products and XWS are based on simulations with coarse horizontal resolution. This makes it difficult to specify a "true" storm location. A slight difference in the location of the LMSLP can already have a significant effect on the absolute distance in kilometres. In relation to grid point distances however, the differences are rather small. The distances between LMSLP in CFSv2 and XWS as stated in Table 4 (130 km) and Table 5 (220 km) are equivalent to approximately two to four grid points.

The comparison with the buoy locations shows that the impact of the introduction of "Christian" into WRF was found to be largest for locations near the storm (Figure 9). At locations away from the storm all simulations were in 
agreement, and performed reasonably well, highlighting that such a small and fast moving storm has little impact far away from the storm centre.

In addition to the model setups discussed in this study, a few additional setups could be worth exploring. For example, different horizontal resolutions of the forcing data could have an impact on the introduction of the storm to the model. Matte et al. (2017) showed that the relative change in resolution between the forcing data and the LAM (in their case the Canadian RCM5) influences the spatial spin-up of features away from the LBCs. In this study, WRF has a resolution of $18 \mathrm{~km}$ and CFSv2 is provided every 0.5 degree, resulting in a resolution jump between J=2.5 to 3.0 . This resolution jump of factor three is also one of the recommended resolution jumps used within WRF i.e. between subsequent nested domains (see e.g. best practices by Gill and Pyle (2012)) and is therefore a quite representative resolution jump. The "J3" scenario in Matte et al. (2017) had a similar resolution jump. In that scenario, they estimated that the spatial spin-up of small scale structures in the relative vorticity field at $700 \mathrm{hPa}$ was between $50-60$ grid cells for an hourly update frequency and 80-90 grid cells for a 6 hourly update. Their spin-up region is measured from the "hard" border, i.e. including the Davies relaxation zone. In the current study, the LAM domain is rather small (150x100 grid points). Combined with the previously discussed spin-up challenges due to the fast travel speed of "Christian", it can be assumed that the current model will not fully develop the small-scale features, especially in the cases with an update every 6 hours. While an increase of the domain size is needed to cope with the additionally required spatial on.n-up, the benefits have to be weighted against the added computational costs of larger domains. However, the question of how the spatial spin-up of small-scales affects the introduction of the larger scale structures in this case remains for future work.

Overall, the results suggest that using a higher update frequency is the best approach for introducing storms into the model domain. However, that requires higher resolution data to be available, which is not always the case. When higher frequency data is not available, spectral nudging provides a method of correcting spatial distortions, but comes at the expense of spatial smoothing. Alternatively, if the model domain is relatively large and the focus area of interest is sufficiently far away from the border, targeted restarting of the simulation, as presented in Termonia et al. (2009) could be used. Instead of introducing the large-scale structure from the outside, via the LBCs, targeted restarts allow the model to be initialised with the large-scale structure already in the model domain. This however requires 
enough domain space and simulation time to spin up the smaller-scales that were lost due to the restart (Termonia et al. (2009)).

\section{7 | CONCLUSION}

Methods covering spatial and temporal adjustments are investigated to explore the challenge of introducing fast moving large-scale meteorological information into a limited area model. This study highlights specific challenges related to the storm passing through the lateral boundary corner. While reallocating the domains for each particular simulation is straightforward, it is of limited use for general investigations. Spectral nudging provides a useful tool to tackle spatial distortions, but needs to be be weighted against the related spatial smoothing with its negative effects on storm intensification. This emphasises that studies of extremes require a different LBC introduction strategy compared to studies of mean state investigations, where additional spatial smoothing is less influential. An increased update frequency of the lateral boundary conditions is shown to be very crucial and efficient in the situation of fast propagating systems. It reduces effects of artificially created distortions and smoothing caused by temporal interpolation and is therefore the recommended method for addressing the "corner issue" if high temporal resolution data is available.

\section{acknowledgements}

Great thanks goes to Danish ForskEL project XWiWA (PSO-12020) and OffshoreWake (PSO-12521) and the people and institutions behind the Extreme Wind Storms Catalogue providing the meteorological details of the investigated storm. Point measurements used were made available by the EMODnet Physics project, www.emodnetphysics.eu/map, funded by the European Commission Directorate General for Maritime Affairs and Fisheries. The

Climate Forecast System Version 2 Forecast Products used in this publication are downloaded from UCAR/NCAR Research Data Archive. The first author likes to thank the researchers at the Mesoscale \& Microscale Meteorology Division at NCAR for their help. The fourth author acknowledges "Wave Boundary Layer Model in Typhoon Condition 
and its Application in Wind-Wave Coupling System, GY0219Q06". The first author thanks also the developer team behind the python packages matplotlib (Hunter (2007)) and cartopy (Met Office (2010 - 2015)). The authors have no conflict of interest to report.

\section{references}

AIR Worldwide (cited 2018) Air Loss Estimates in Real Time (ALERT) online service. URL: http://alert . air-worldwide . com/ EventSummary $\cdot \operatorname{aspx} ? e=723 \& t p=72 \& c=1$

ALADIN International Team (1997) The ALADIN project : Mesoscale modelling seen as a basic tool for weather forecasting and atmospheric research. WMO Bull., 46, 317-324.

Alexandru, A., de Elia, R., Laprise, R., Separovic, L. and Biner, S. (2009) Sensitivity Study of Regional Climate Model Simulations to Large-Scale Nudging Parameters. Mon. Wea. Rev., 137, 1666-1686.

Chikhar, K. and Gauthier, P. (2017) Impact of Lateral Boundary Conditions on Regional Analyses. Mon. Wea. Rev., 145, 13611379.

Consortium for Small Scale Modeling (COSMO) (cited 2018) Operational Applications within COSMO. URL: http://www . cosmo-model.org/content/tasks/operational/default.htm.

Davies, H. C. and Turner, R. E. (1977) Updating prediction models by dynamical relaxation: an examination of the technique. Quart. J. Roy. Meteor. Soc., 103, 225-245.

Davies, T. (2014) Lateral boundary conditions for limited area models. Quart. J. Roy. Meteor. Soc., 140, 185-196. URL: http: //doi.wiley.com/10.1002/qj. 2127.

Dee, D. P., Uppala, S. M., Simmons, A. J., Berrisford, P., Poli, P., Kobayashi, S., Andrae, U., Balmaseda, M. A., Balsamo, G., Bauer, P., Bechtold, P., Beljaars, A. C. M., van de Berg, L., Bidlot, J., Bormann, N., Delsol, C., Dragani, R., Fuentes, M., Geer, A. J., Haimberger, L., Healy, S. B., Hersbach, H., Hólm, E. V., Isaksen, L., Kållberg, P., Köhler, M., Matricardi, M., McNally, A. P., Monge-Sanz, B. M., Morcrette, J.-J., Park, B.-K., Peubey, C., de Rosnay, P., Tavolato, C., Thépaut, J.-N. and Vitart, F. (2011) The ERA-Interim reanalysis: configuration and performance of the data assimilation system. Quart. J. Roy. Meteor. Soc., 137, 553-597.

Denis, B., Laprise, R., Caya, D. and Côté, J. (2002) Downscaling ability of one-way nested regional climate models: The BigBrother Experiment. Climate Dyn., 18, 627-646. 
Dudhia, J. (2017) Overview of WRF physics. In SUMMER 2017 BASIC WRF TUTORIAL. URL: https://www2.mmm.ucar.edu/ wrf/users/tutorial/201707/physics.pdf.

EMODnet (cited 2018) The european marine observation and data network. URL: www .emodnet-physics.eu/Portal.

Feser, F. (2006) Enhanced detectability of added value in limited-area model results separated into different spatial scales. Mon. Wea. Rev., 134, 2180-2190.

Gill, D. and Pyle, M. (2012) Nesting in WRF. In JANUARY 2012 BASIC WRF TUTORIAL. URL: https://www2.mmm.ucar.edu/ wrf/users/tutorial/201201/WRFNesting.ppt.pdf.

Giorgi, F. (2019) Thirty Years of Regional Climate Modeling: Where Are We and Where Are We Going next? J. Geophys. Res., 124, 5696-5723.

Gómez, B. and Miguez-Macho, G. (2017) The impact of wave number selection and spin-up time in spectral nudging. Quart. J. Roy. Meteor. Soc., 143, 1772-1786.

Gustafsson, N. (1990) Sensitivity of limited area model data assimilation to lateral boundary condition fields. Tellus, 42, 109115.

Gustafsson, N., Källén, E. and Thorsteinsson, S. (1998) Sensitivity of forecast errors to initial and lateral boundary conditions. Tellus, 50, 167-185.

Haeseler, S. and Lefebvre, C. (2013) Heavy storm CHRISTIAN on 28 October 2013. Tech. Rep. October, German Meteorological Office. URL: https://www.dwd.de/EN/ourservices/specialevents/storms/20131028_CHRISTIAN_europe_en.pdf? _-_blob=publicationFile\&v=7.

Hewson, T., Magnusson, L., Breivik, O., Prates, F., Tsonevsky, I. and de Vries, H. (2014) Windstorms in northwest Europe in late 2013. In ECMWF Newsletter (ed. Riddaway;Bob), no. 139 in ECMWF Newsletter, chap. Meteorolog, 22-28. Reading, Berkshire RG2 9AX, UK: European Centre for Medium-Range Weather Forcaset (ECMWF).

Hoskins, B. J. and Hodges, K. I. (2002) New Perspectives on the Northern Hemisphere Winter Storm Tracks. J. Atmos. Sci., 59, 1041-1061.

Hunter, J. D. (2007) Matplotlib: A 2d graphics environment. Comput. Sci. Eng., 9, 90-95.

lacono, M. J., Delamere, J. S., Mlawer, E. J., Shephard, M. W., Clough, S. A. and Collins, W. D. (2008) Radiative forcing by long-lived greenhouse gases: Calculations with the AER radiative transfer models. J. Geophys. Res., 113, D13103. 
Imberger, M. (2017) Modeling rough weather over the North Sea - using COAWST for offshore wind energy applications. Master thesis report, Wind Energy Department, Technical University of Denmark, Denmark. URL: http: //production.datastore . cvt.dk/oafilestore?oid=596dea925010df6dc860f342\&targetid=596dea925010df6dc860f345.

Kain, J. S. (2004) The Kain-Fritsch Convective Parameterization: An Update. J. Appl. Meteor., 43, 170-181.

Källén, E. (1996) HIRLAM DOCUMENTATION MANUAL. Tech. rep., HIRLAM Consortium. URL: http://hirlam.org/index. php/hirlam-documentation/doc_download/1531-hirlam-documentation-system-2-5-june-1996.

Laprise, R. (2003) Resolved Scales and Nonlinear Interactions in Limited-Area Models. J. Atmos. Sci., 60, 768-779.

Larsén, X., Rodolfo, B., Du, J., Kelly, M. C., Kofoed-Hansen, H., Larsen, S. E., Karagali, I., Badger, M., Hahmann, A. N., Imberger, M., Tornfeldt, S. J., Jackson, S., Volker, P., Svenstrup Petersen, O., Jenkins, A. and Graham, A. (2017a) Extreme winds and waves for offshore turbines: Coupling atmosphere and wave modeling for design and operation in coastal zones. Tech. rep., Technical University of Denmark, Roskilde, Denmark. URL: https://orbit.dtu.dk/ws/files/139272513/FinalReport_ PS012020_XWiWa_20171031.pdf.

Larsén, X. G., Du, J., Bolaños, R., Imberger, M., Kelly, M. C., Badger, M. and Larsen, S. (2019) Estimation of offshore extreme wind from wind-wave coupled modeling. Wind Energy, 22, 1043-1057.

Larsén, X. G., Du, J., Bolaños, R. and Larsen, S. (2017b) On the impact of wind on the development of wave field during storm Britta. Ocean Dynam., 67, 1407-1427.

Matte, D., Laprise, R., Thériault, J. M. and Lucas-Picher, P. (2017) Spatial spin-up of fine scales in a regional climate model simulation driven by low-resolution boundary conditions. Climate Dyn., 49, 563-574.

Met Office (2010 - 2015) Cartopy: a cartographic python library with a matplotlib interface. Exeter, Devon. URL: http:// scitools.org.uk/cartopy.

Miguez-Macho, G., Stenchikov, G. L. and Robock, A. (2004) Spectral nudging to eliminate the effects of domain position and geometry in regional climate model simulations. J. Geophys. Res., 109, 1-15.

Nakanishi, M. and Niino, H. (2006) An improved Mellor-Yamada Level-3 model: Its numerical stability and application to a regional prediction of advection fog. Bound.-Layer Meteorol., 119, 397-407.

Roberts, J. F., Champion, A. J., Dawkins, L. C., Hodges, K. I., Shaffrey, L. C., Stephenson, D. B., Stringer, M. A., Thornton, H. E. and Youngman, B. D. (2014) The XWS open access catalogue of extreme European windstorms from 1979 to 2012 . Nat. Hazard Earth Sys., 14, 2487-2501. 
Saha, S., Moorthi, S., Wu, X., Wang, J., Nadiga, S., Tripp, P., Behringer, D., Hou, Y.-T., Chuang, H.-y., Iredell, M., Ek, M., Meng, J., Yang, R., Mendez, M. P., van den Dool, H., Zhang, Q., Wang, W., Chen, M. and Becker, E. (2011) Ncep climate forecast system version 2 (cfsv2) 6-hourly products. URL: https://doi .org/10.5065/D61C1TXF. Last accessed: 20 Januar 2017.

- (2014) The NCEP Climate Forecast System Version 2. J. Climate, 27, 2185-2208.

Skamarock, W. C. (2004) Evaluating Mesoscale NWP Models Using Kinetic Energy Spectra. Mon. Wea. Rev., 132, 3019-3032.

Skamarock, W. C., Klemp, J. B., Dudhia, J., Gill, D. O., Barker, D. M., Duda, M. G., Huang, X.-Y., Wang, W. and Powers, J. (2008) A Description of the Advanced Research WRF Version 3. Tech. rep., Mesoscale and Microscale Meteorology Division, National Center for Atmospheric Research, Boulder, Colorado, USA. URL: http://dx.doi.org/10.5065/D68S4MVH.

Stauffer, D. R. and Seaman, N. L. (1990) Use of four-dimensional data assimilation in a limited-area mesoscale model. Part I: experiments with synoptic-scale data.

von Storch, H., Langenberg, H. and Feser, F. (2000) A Spectral Nudging Technique for Dynamical Downscaling Purposes. Mon. Wea. Rev., 128, 3664-3673.

Termonia, P. (2003) Monitoring and Improving the Temporal Interpolation of Lateral-Boundary Coupling Data for Limited-Area Models. Mon. Wea. Rev., 131, 2450-2463.

Termonia, P., Deckmyn, A. and Hamdi, R. (2009) Study of the Lateral Boundary Condition Temporal Resolution Problem and a Proposed Solution by Means of Boundary Error Restarts. Mon. Wea. Rev., 137, 3551-3566.

Tewari, M., Chen, F., Wang, W., Dudhi, J., LeMone, M., Mitchell, K., Ek, M., Gayno, G., Wegiel, J. and Cuenca, R. H. (2004) Implementation and verification of the unified Noah land surface model in the WRF model. In 20th Conference on Weather Analysis and Forecasting/16th Conference on Numerical Weather Prediction. URL: http://n2t.net/ark: /85065/d7fb523p.

Thompson, G., Field, P. R., Rasmussen, R. M. and Hall, W. D. (2008) Explicit Forecasts of Winter Precipitation Using an Improved Bulk Microphysics Scheme. Part II: Implementation of a New Snow Parameterization. Mon. Wea. Rev., 136, 50955115.

Tudor, M. and Termonia, P. (2010) Alternative Formulations for Incorporating Lateral Boundary Data into Limited-Area Models. Mon. Wea. Rev., 138, 2867-2882.

UCAR/NCAR/CISL/TDD (2017) The NCAR Command Language (Version 6.4.0). URL: http: //www.ncl .ucar.edu/.

Waldron, K. M., Paegle, J. and Horel, J. D. (1996) Sensitivity of a Spectrally Filtered and Nudged Limited-Area Model to Outer Model Options. Mon. Wea. Rev., 124, 529-547. 
Warner, T. T., Peterson, R. A. and Treadon, R. E. (1997) A Tutorial on Lateral Boundary Conditions as a Basic and Potentially Serious Limitation to Regional Numerical Weather Prediction. Bull. Amer. Meteor. Soc., 78, 2599-2617.

Xu, K.-M. and Randall, D. A. (1996) A Semiempirical Cloudiness Parameterization for Use in Climate Models. J. Atmos. Sci., 53, 3084-3102.

XWS Catalogue (cited 2019) Extreme Wind Storms Catalogue. URL: http://www. europeanwindstorms . org/. Copyright Met Office, University of Reading and University of Exeter. Licensed under Creative Commons CC BY 4.0 International Licence: http://creativecommons.org/licenses/by/4.0/deed.en_GB. 
TABLE 1 Summary of model settings regarding spatial and temporal parameters and physics

\begin{tabular}{lc}
\hline Argument & Value \\
\hline WRF Version & 3.7 .1 \\
\hline Forcing data & CFSv2 \\
\hline Spatial Settings & $2700 \mathrm{~km} \times 1800 \mathrm{~km}$ \\
\hline Domain size & $\Delta x=\Delta y=18 \mathrm{~km}$ \\
\hline Horizontal resolution & $150 \times 100$ \\
\hline Grid points & 52 \\
\hline Vertical model level & \\
\hline Temporal Settings & $36 \mathrm{~h}$ \\
\hline Simulation time (incl. spin-up) & $12 \mathrm{~h}$ \\
\hline Spin-up time & every $6 \mathrm{hours}$ \\
\hline LBC update frequency & \\
\hline Physics & New Thompson \\
\hline Microphysics & RRTMG \\
\hline Radiation & Kain-Fritsch \\
\hline Cumulus parameterisation & Noah LSM \\
\hline Land surface & MYNN \\
\hline PBL-Scheme & \\
\hline
\end{tabular}

This article is protected by copyright. All rights reserved. 
TAB LE 2 Overview about all performed simulations with their identifier used to address the simulation in the text and a list of key elements characterising the simulation.

\section{Identifier}

REF

REF-South

NUD100km

HalfRelaxZone

2xRelaxZone

CFSv2-3h

\section{Characteristics}

reference simulation, faces "corner issue", obtained by running WRF with the solid domain in Figure 1, 6 hourly LBC update

like "REF" but with a southwards shifted domain to avoid "corner issue", corresponds to dashed domain in Figure 1, 6 hourly LBC update

like "REF" but with spectral nudging of $U, V, \theta$ and geopotential height, nudging above $100 \mathrm{~km}$ affects all vertical model levels above the planetary boundary layer, 6 hourly LBC update like "REF" but with 50\% relaxation zone width ( 2 instead of 4 grid cells), 6 hourly LBC update like "REF" but with doubled relaxation zone width (8 instead of 4 grid cells), 6 hourly LBC update

like "REF" but with 3-hourly update of the lateral boundary conditions (instead of every 6 hours)

CFSv2-1h

TAB LE 3 Estimated local minimum sea level pressure obtained from the WRF simulations, the CFSv2 forcing data and the XWS catalogue at 1800 UTC 27 October 2013 and 0000 UTC 28 October 2013. Values in bold (italic) indicate values which are at least $3 \mathrm{hPa}$ lower (higher) than the value of the CFSv2 forcing data.

\begin{tabular}{lcc}
\hline \hline Identifier & \multicolumn{2}{c}{ Local minimum sea level pressure (in hPa) at } \\
& 1800 UTC 27 Oct 2013 & 0000 UTC 28 Oct 2013 \\
\hline REF & 992 & 986 \\
\hline REF-South & 989 & 981 \\
\hline NUD100km & 991 & 985 \\
\hline HalfRelaxZone & 990 & 983 \\
\hline 2xRelaxZone & 992 & 987 \\
\hline CFSv2-3h & 987 & 981 \\
\hline CFSv2-1h & 985 & 979 \\
\hline CFSv2 & 988 & 984 \\
\hline XWS & 990 & 983 \\
\hline
\end{tabular}


TAB LE 4 Estimated location of local minimum sea level pressure (LMSLP) obtained from the WRF simulations, the CFSV2 forcing data and the XWS catalogue at 1800 UTC 27 October 2013. The great circle distances to XWS $\left(d_{X W S}\right)$ and CFSv2 ( $\left.d_{C F S v 2}\right)$ locations rounded to closest full $10 \mathrm{~km}$ are given as well.

\begin{tabular}{|c|c|c|c|}
\hline \multirow[t]{2}{*}{ Identifier } & \multicolumn{3}{|c|}{ Location of LMSLP (1800 UTC 27 October 2013) } \\
\hline & location & $d_{C F S v 2}[\mathrm{~km}]$ & $d_{X w s}[\mathrm{~km}]$ \\
\hline REF & $49.08^{\circ} \mathrm{N} 10.83^{\circ} \mathrm{W}$ & 30 & 110 \\
\hline REF-South & $49.14^{\circ} \mathrm{N} 9.83^{\circ} \mathrm{W}$ & 50 & 190 \\
\hline NUD100km & $49.68^{\circ} \mathrm{N} 9.68^{\circ} \mathrm{W}$ & 100 & 220 \\
\hline HalfRelaxZone & $49.13^{\circ} \mathrm{N} 10.33^{\circ} \mathrm{W}$ & 20 & 150 \\
\hline 2xRelaxZone & $48.06^{\circ} \mathrm{N} 11.10^{\circ} \mathrm{W}$ & 110 & 120 \\
\hline CFSv2-3h & $48.92^{\circ} \mathrm{N} 10.79^{\circ} \mathrm{W}$ & 20 & 110 \\
\hline CFSv2-1h & $48.90^{\circ} \mathrm{N} 11.04^{\circ} \mathrm{W}$ & 40 & 90 \\
\hline CFSv2 & $49.0^{\circ} \mathrm{N} 10.5^{\circ} \mathrm{W}$ & - & 130 \\
\hline XWS & $48.8^{\circ} \mathrm{N} 12.3^{\circ} \mathrm{W}$ & 130 & - \\
\hline
\end{tabular}

TAB LE 5 Estimated location of local minimum sea level pressure (LMSLP) obtained from the WRF simulations, the CFSv2 forcing data and the XWS catalogue at 0000 UTC 28 October 2013. The great circle distances to XWS $\left(d_{X W S}\right)$ and CFSv2 ( $\left.d_{C F S v 2}\right)$ locations rounded to closest full $10 \mathrm{~km}$ are given as well.

\begin{tabular}{|c|c|c|c|}
\hline \multirow[t]{2}{*}{ Identifier } & \multicolumn{3}{|c|}{ Location of LMSLP (0000 UTC 28 October 2013) } \\
\hline & location & $d_{C F S v 2}[\mathrm{~km}]$ & $d_{X w s}[\mathrm{~km}]$ \\
\hline REF & $50.79^{\circ} \mathrm{N} 5.47^{\circ} \mathrm{W}$ & 160 & 60 \\
\hline REF-South & $51.66^{\circ} \mathrm{N} 3.18^{\circ} \mathrm{W}$ & 30 & 250 \\
\hline NUD100km & $51.69^{\circ} \mathrm{N} 3.18^{\circ} \mathrm{W}$ & 30 & 310 \\
\hline HalfRelaxZone & $51.50^{\circ} \mathrm{N} 4.22^{\circ} \mathrm{W}$ & 50 & 180 \\
\hline 2xRelaxZone & $51.54^{\circ} \mathrm{N} 2.64^{\circ} \mathrm{W}$ & 60 & 270 \\
\hline CFSv2-3h & $51.69^{\circ} \mathrm{N} 3.45^{\circ} \mathrm{W}$ & 20 & 230 \\
\hline CFSv2-1h & $51.86^{\circ} \mathrm{N} 3.19^{\circ} \mathrm{W}$ & 50 & 260 \\
\hline CFSv2 & $51.5^{\circ} \mathrm{N} 3.5^{\circ} \mathrm{W}$ & - & 220 \\
\hline XWS & $50.4^{\circ} \mathrm{N} 6.1^{\circ} \mathrm{W}$ & 220 & - \\
\hline
\end{tabular}

This article is protected by copyright. All rights reserved. 


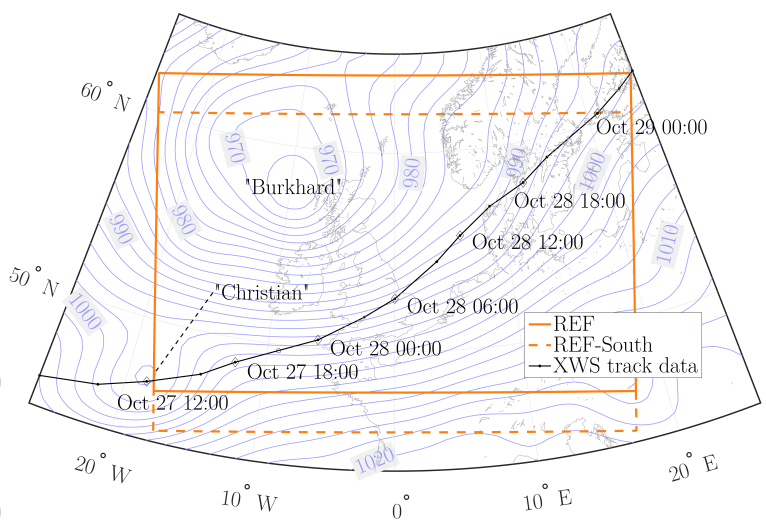

FIGURE 1 Blue: Contours of modelled mean sea level pressure ( $\mathrm{hPa}$ ) obtained from CFSv2 6-h forecast data at 1200 UTC 27 October 2013. Contours are drawn every $2 \mathrm{hPa}$. The locations of the two low pressure systems "Burkhard" and "Christian" are indicated. Black line: Extract of the storm track "Christian" covering 0600 UTC 27 October 2013 to 0600 UTC 29 October 2013 from the XWS Catalogue (cited 2019). Due to spatial constraints, dates are represented in the short form MMM DD HH:MM. All dates are given in UTC. The hollow data point ' 0 ' is indicating a missing data point at 2100 UTC 27 October 2013 in the data set. Orange: WRF domains "REF" (solid) and "REF-South" (dashed).
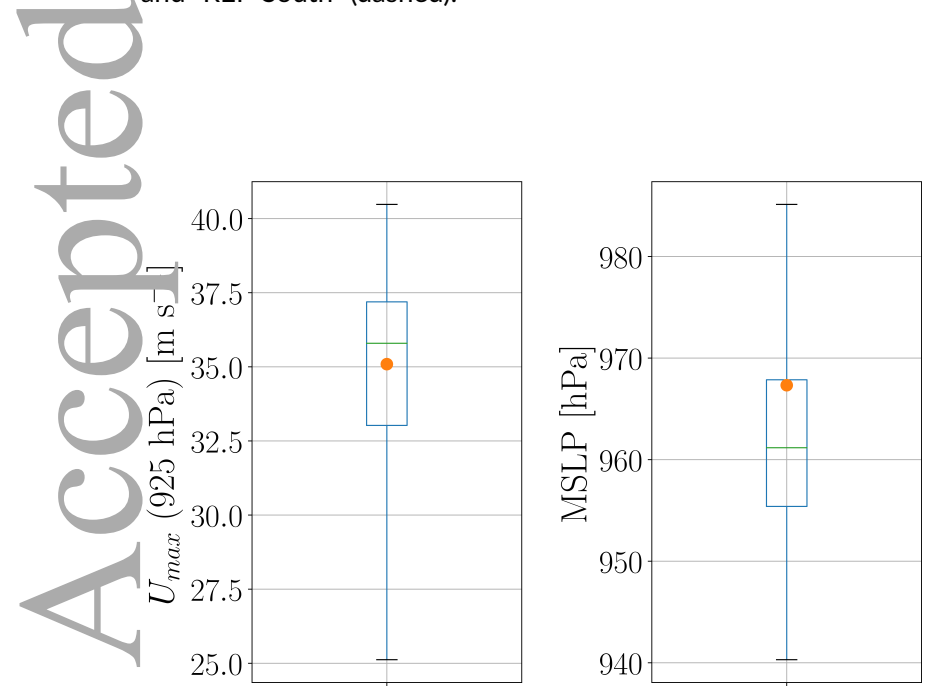

FIGURE 2 Box plots of life-time lowest minimum sea level pressure (MSLP) and life-time highest maximum wind speed $\left(U_{\max }\right)$ at $925 \mathrm{hPa}$ level determined from all listed storms in the XWS catalogue (52 in total): median values (green), the interquartile range (IQR, blue box) as well as global minimum and maximum (whiskers). The orange dots represent the extreme values of storm "Christian". 
1200 UTC 27 October 2013

(a)

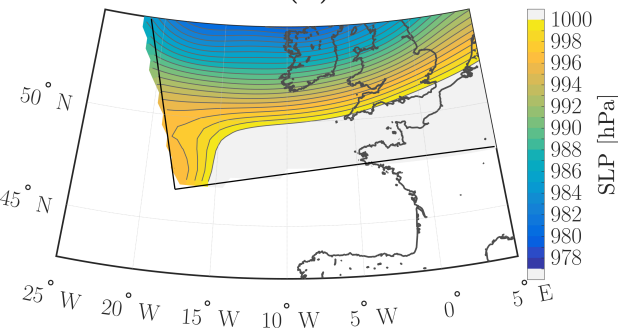

(c)

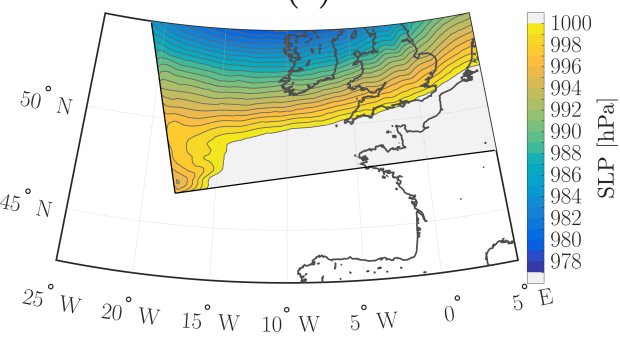

(e)

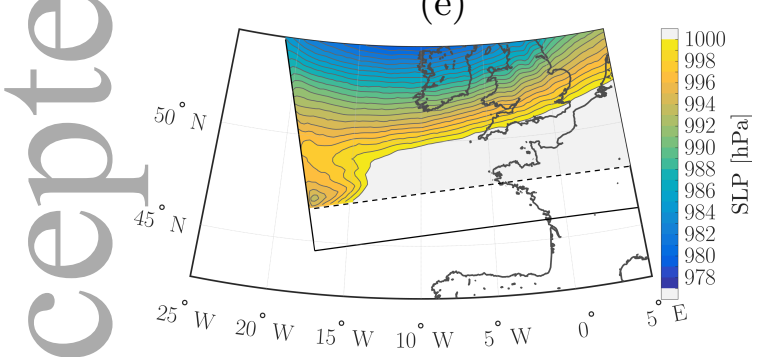

0000 UTC 28 October 2013

(b)

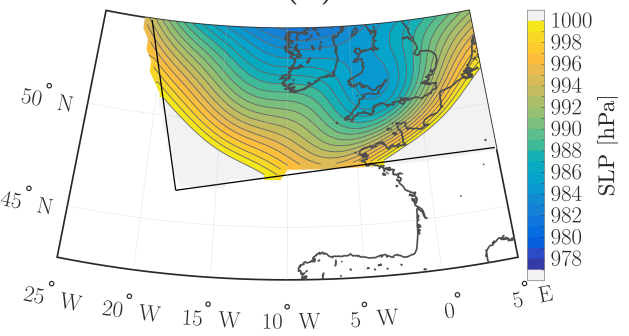

(d)

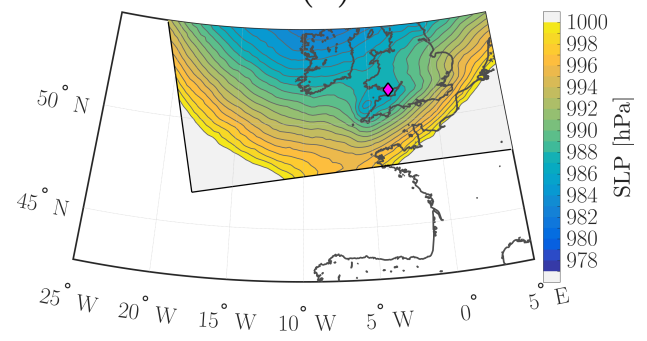

(f)

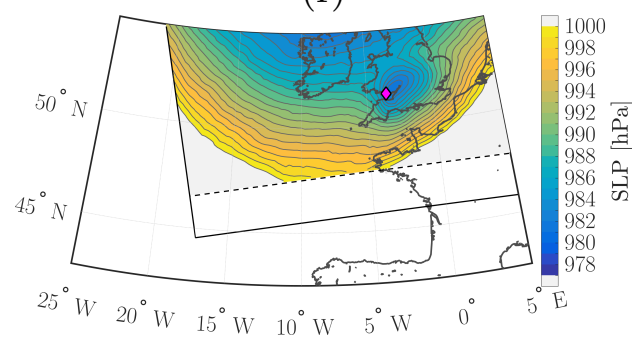

FIGURE 3 Contour plot of modelled sea level pressure field obtained at 1200 UTC 27 October 2013 (left column) and 0000 UTC 28 October 2013 (right column). (a),(b): Sea level pressure field obtained from the CFSv2 forcing data. The black frame indicates the location of the WRF reference domain. (c),(d): Results obtained from "REF". (e),(f): Results obtained from "REF-South". The pink diamond in (d) and (f) marks the position of the minimum sea level pressure determined from CFSv2 data. The dashed line in the bottom row indicates the southern border of "REF" used in the other simulations. Values beyond the given limits are depicted in grey. 
(a)

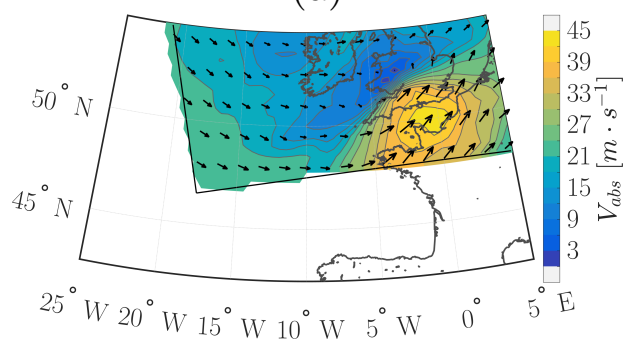

(c)

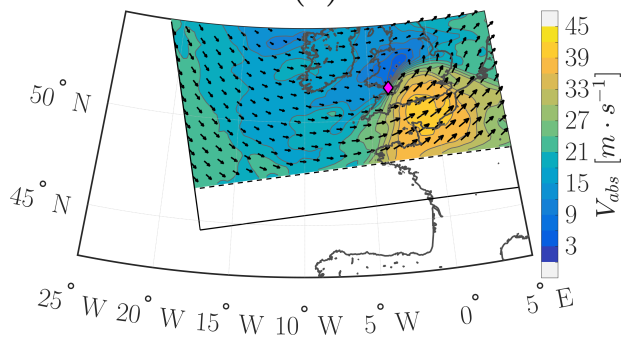

(e)

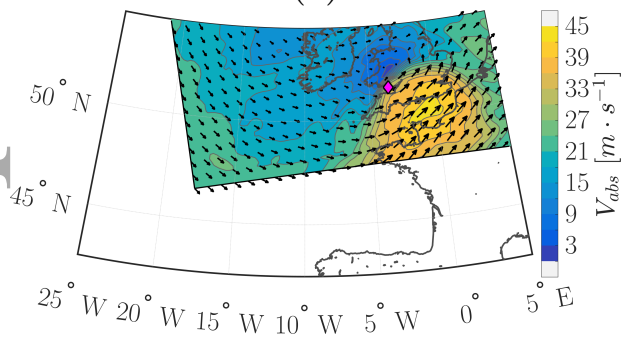

(b)

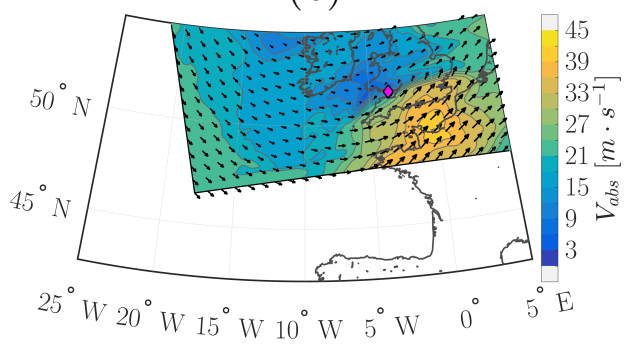

(d)

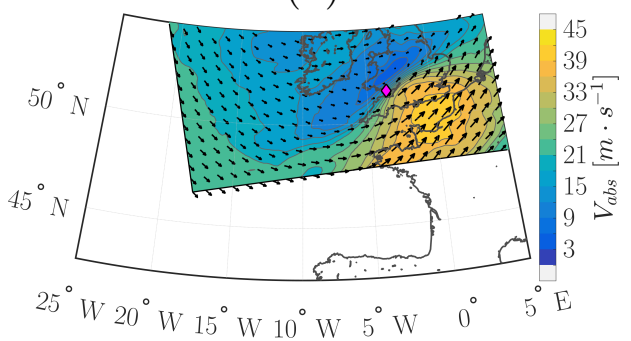

(f)

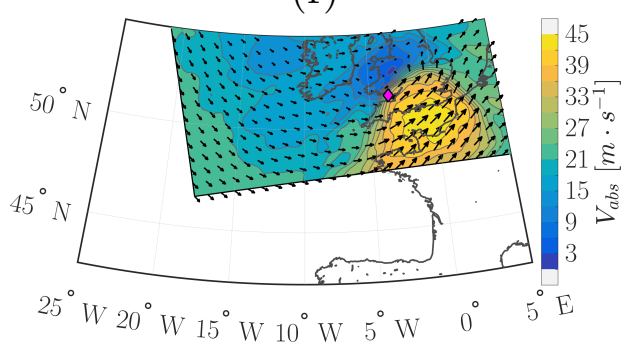

FIGURE 4 Modelled absolute wind speed (contours) and wind direction (vectors) obtained from (a) CFSv2 forcing data in comparison with the WRF results from (b) "REF", (c) "REF-South", (d) "NUD100km", (e) "CFSv2-3h" and (f) "CFSv2-1h". All values are obtained at $850 \mathrm{hPa}$ at 0000 UTC 28 October 2013. The pink diamond indicates the location of the minimum sea level pressure determined in CFSv2. The dashed line in (c) indicates the southern border of "REF" used in the other simulations. 
(a)

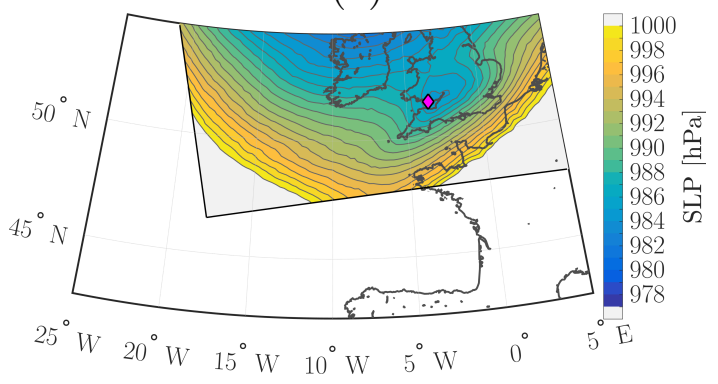

(b)

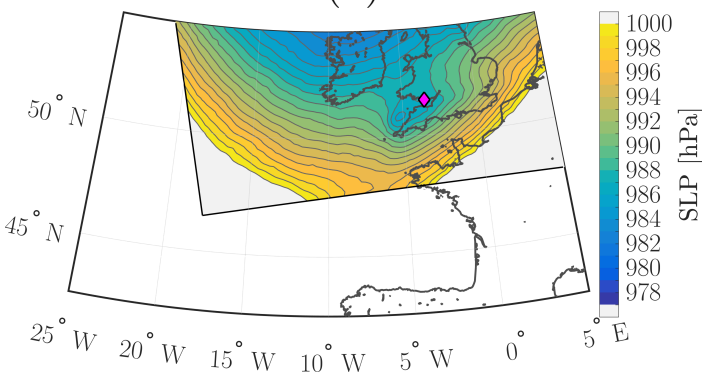

(c)

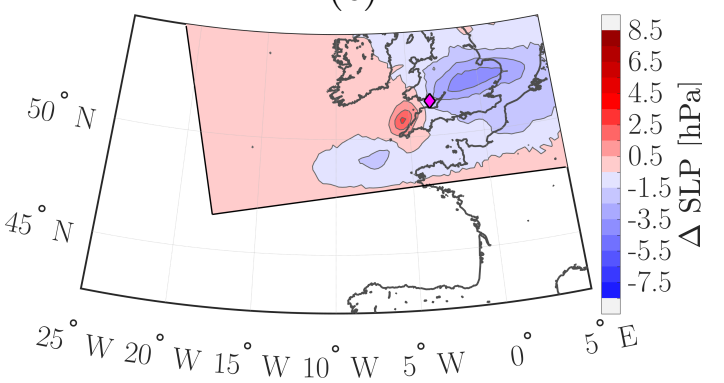

FIGURE 5 Contour plot of modelled sea level pressure field obtained from (a) "NUD100km" and (b) "REF" as well as (c) the difference between the two ("NUD100km" minus "REF"). All fields are determined at 0000 UTC 28 October 2013. The pink diamond indicates the location of the minimum sea level pressure determined in CFSv2. Values beyond the given limits are depicted in grey. 


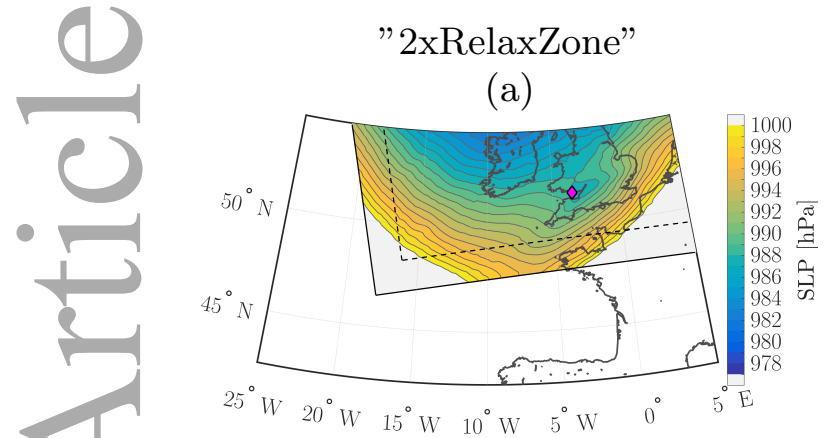

(c)

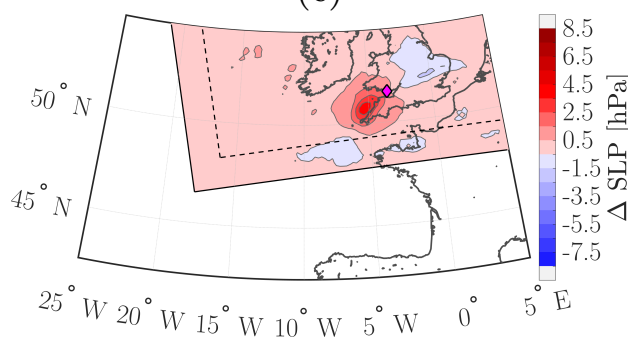

"HalfRelaxZone"

(b)

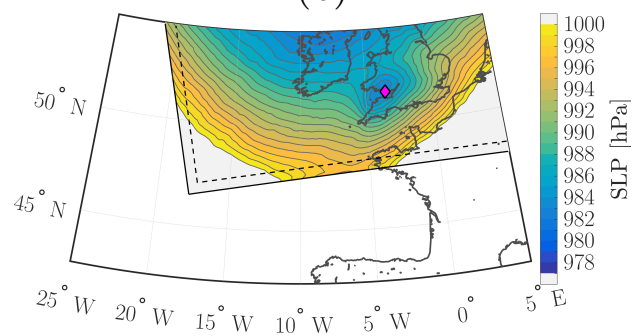

(d)

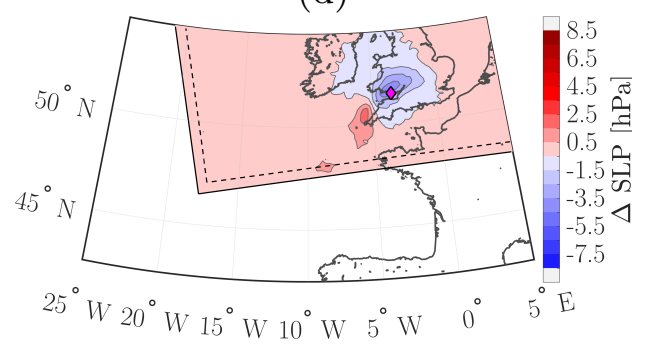

FIGURE 6 Contour plot of modelled sea level pressure determined by (a) "2xRelaxZone" and (b) "HalfRelaxZone" as well as (c) "2xRelaxZone" minus "REF" and (d) "HalfRelaxZone" minus "REF". All fields are determined at 0000 UTC 28 October 2013. Positive $\triangle S L P$ indicates higher SLP values in "2xRelaxZone" respectively "HalfRelaxZone". The pink diamond marks the location of the minimum sea level pressure determined in CFSv2. The dashed lines depict the location of the margin of the relaxation zone in "2xRelaxZone" respectively "HalfRelaxZone". Values beyond the given limits are depicted in grey. 
(a)

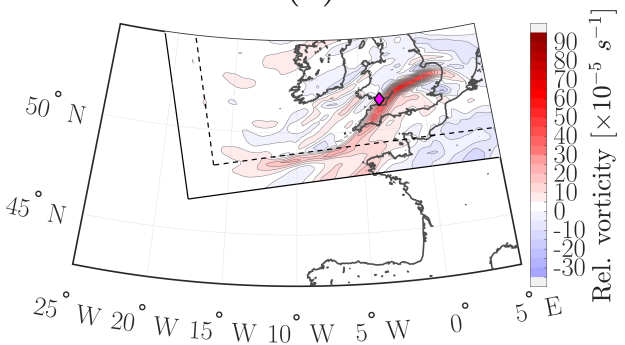

(c)

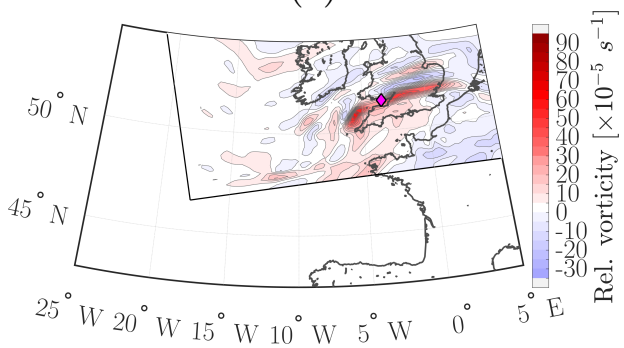

(b)

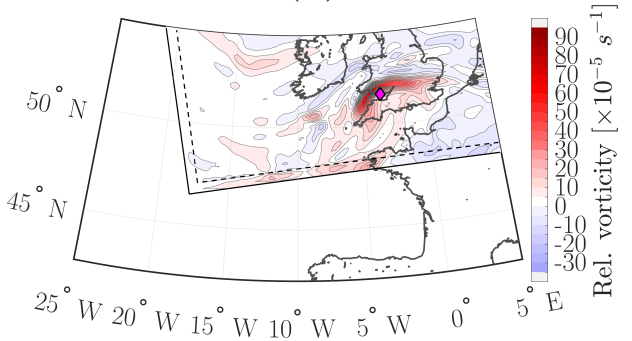

(d)

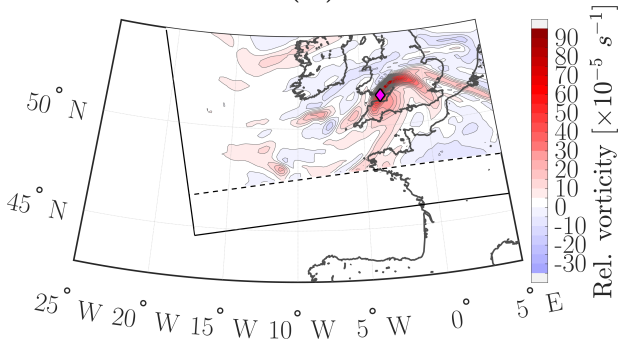

FIGURE 7 Contour plot of modelled relative vorticity at $850 \mathrm{hPa}$ determined by (a) "2xRelaxZone" and (b) "HalfRelaxZone" compared to (c) "REF" and (d) "REF-South". All fields are determined at 0000 UTC 28 October 2013. The pink diamond indicates the location of the minimum sea level pressure determined in CFSv2. The dashed lines in (a),(b) depict the location of the margin of the relaxation zone while the dashed line in (d) marks the southern domain border of "REF" which is used in the other simulations. 
(a)

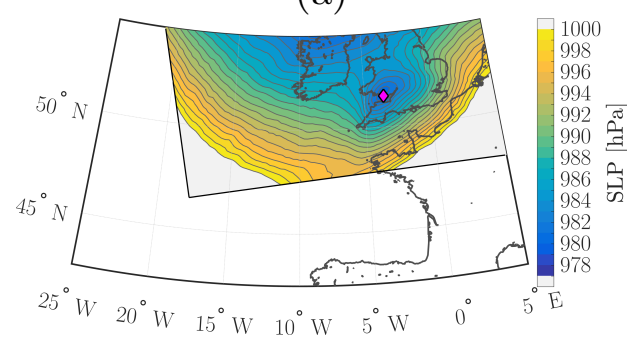

(c)

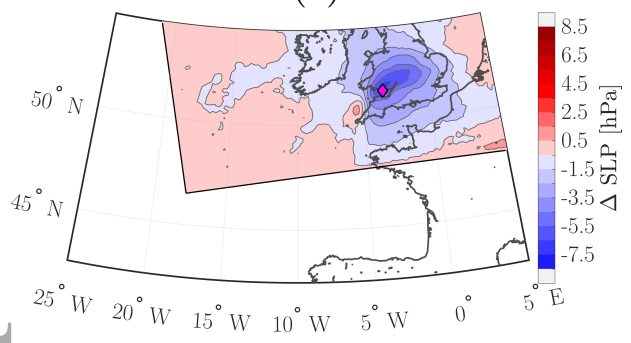

(b)

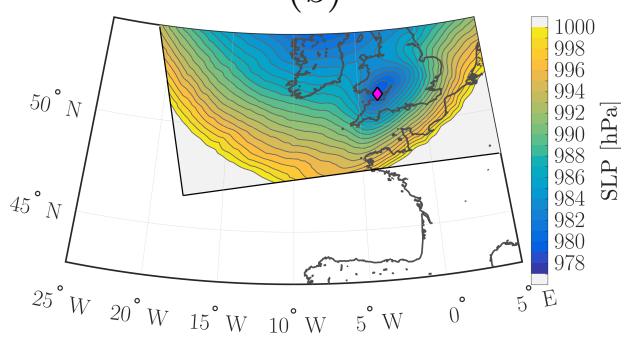

(d)

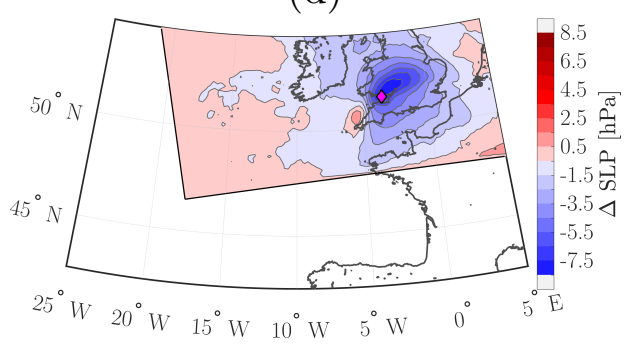

FIGURE 8 Contour plot of modelled SLP obtained from (a) "CFSv2-3h" (update every 3 hours), (b) "CFSv2-1h" (update every hour) and SLP difference between (c) "CFSv2-3h" and "REF" and (d) "CFSv2-1h" and "REF". All fields are determined at 0000 UTC 28 October 2013. The pink diamond marks the location of the minimum sea level pressure determined in CFSv2. Positive $\triangle S L P$ indicates higher SLP values in "CFSv2-3h" respectively "CFSv2-1h". Values beyond the given limits are depicted in grey. 

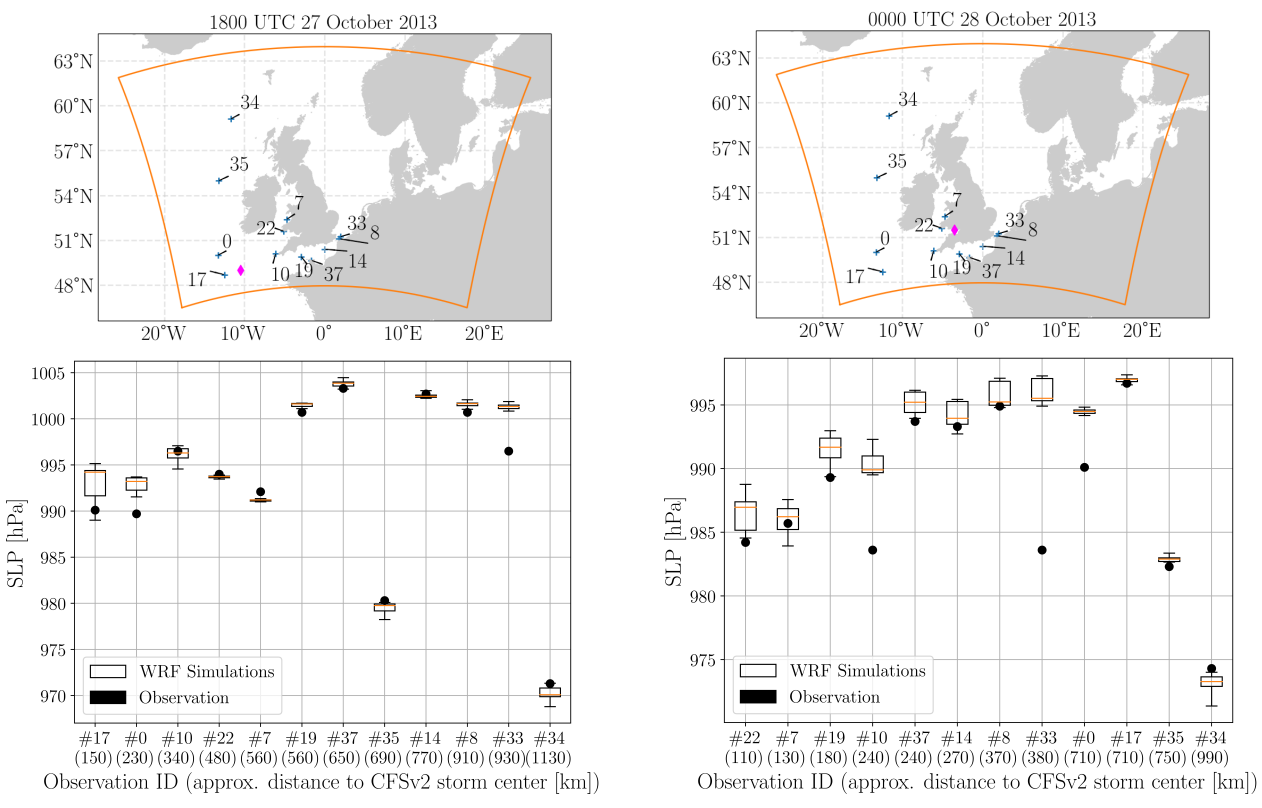

FIGURE 9 Top row: Location of the CFSv2 storm centre (pink diamond) at 1800 UTC 27 October 2013 (left) and 0000 UTC 28 October 2013 (right) in relation to the buoys (blue plus) and the WRF domain (orange frame). Bottom row: Box plot showing median (orange), first and third quartile (black box) and $\mathrm{min} / \mathrm{max}$ values (whiskers) of SLP estimation of all seven simulations at the list of buoy stations at 1800 UTC 27 October 2013 (left) and 0000 UTC 28 October 2013 (right). The buoys are sorted with increasing distance to the CFSv2 storm centre at that point in time. The black dots depict the measured value for the SLP at the given buoy. 